\title{
Business Model Development and Validation in Digital Entrepreneurship
}

\author{
Lutz Göcke and Robin Weninger
}

\begin{abstract}
Every venture is developed under high uncertainty and causal ambiguity. A large majority of digital startups leverage the lean startup approach to validate the attractiveness of their venture, to reduce avoidable investments of scarce resources, and to structure the venturing process. Digital entrepreneurs highlight that prioritization and the definition of MVPs are two challenges that entrepreneurs face when applying the lean startup approach. We provide support on these particular challenges through a structured approach-the venture pyramid - to (in)validate digital business models in the face of high uncertainty. Furthermore, we map different types of digital business models with patterns of minimum viable products to inspire digital entrepreneurs and scientists alike. To illustrate our thoughts, we have developed two case studies of German startups that applied a process of rigorous iteration and learning to their venturing processes.
\end{abstract}

\section{Introduction}

A recent study shows that $93 \%$ of digital startups use the lean startup approach to find product-market fit fast, to avoid unnecessary resource investment, or to structure the development process of the venture (Ghezzi 2019). The same study

\section{Göcke $(\bowtie)$}

Chair of Digital Management, Nordhausen University of Applied Sciences, Nordhausen, Germany e-mail: lutz.goecke@hs-nordhausen.de

R. Weninger

Global Institute of Leadership and Technology (GILT), Eschborn, Germany

(C) The Author(s) 2021

M. Soltanifar et al. (eds.), Digital Entrepreneurship, Future of Business and Finance,

https://doi.org/10.1007/978-3-030-53914-6_4 
Table 1 Advantages and disadvantages of applying the lean startup approach (Ghezzi 2019)

\begin{tabular}{l|l}
\hline Advantages & $\begin{array}{l}\text { 1. Reducing time and cost for startup testing (74\%) } \\
\text { 2. Aligning business idea to customer needs }(68 \%) \\
\text { 3. Verifying and pivoting all business model parameters (52\%) } \\
\text { 4. Receiving rounds of financing (39\%) }\end{array}$ \\
\hline Disadvantages & $\begin{array}{l}\text { 1. Defining and designing MVPs }(82 \%) \\
\text { 2. Identifying and engaging early evangelists and trial users }(69 \%) \\
\text { 3. Defining testing priorities and designing tests (52\%) } \\
\text { 4. Missing other market opportunities and threats (39\%) } \\
\text { 5. Obtaining information about the startup sources of advantage (36\%) }\end{array}$ \\
\hline
\end{tabular}

identifies the advantages and disadvantages that digital startups face in the application of the lean startup approach (Ghezzi 2019) (Table 1).

The prioritization, definition, and design of experiments (incl. MVPs) are some of the major challenges that digital entrepreneurs have in the application of the lean startup approach to their business. One founder in the study mentioned that "lean tells you to build an MVP but gives you no clear guidelines or indications whatsoever on how to do so" (Ghezzi 2019). In this article, we offer a structured approach to test digital business ideas and to identify minimum viable products that help a startup within this journey.

\section{2 (Theoretical) Background}

\subsection{Digital Business Models}

A business model can be understood as the core logic of a firm to create and deliver value for its customers and to capture value for itself (Zott et al. 2011; Göcke 2016). When we talk about business models, it is very important to stress out that a business model is not the same as a revenue model. Both terms are getting mixed up very frequently in practice and are often seen as the same, which is not the case (see also Ghaziani and Ventresca 2005). A business model is a holistic perspective on the overall setup of the business and includes every process along the value chain. Various conceptualizations of business models have been developed to guide researchers and practitioners alike to analyze or develop business models (e.g., Chesbrough and Rosenbloom 2002; Teece 2010; Gassmann et al. 2014; Schneider and Spieth 2013). The "Business Model Canvas" of Osterwalder and Pigneur (2011) and the "Lean Canvas" of Maurya (2012) are prominent conceptualizations that are widely spread in practice. Central to most of these conceptualizations are the components value proposition, value creation, and value capture (Clauss 2017). This includes the cost model and the revenue model. The revenue model is thus a component of every business model. Every company can run on multiple business models (think different products) and on multiple revenue streams. Also, a single business model can be run with multiple revenue models. Whenever we work on a 
business model, it is required to also work on the revenue model. However, if we work on a revenue model, it is not necessarily required to change the whole business model (Cavalcante et al. 2011). Every entrepreneur's task is to get the equation in a business model right. A company's value proposition needs to be valuable for a user and create a proper willingness to pay, which is able to compensate the costs of the value creation and captured with a proper revenue model. All components need to be coherently aligned to a business model fit.

Digital business models define how a firm creates and captures value through extensive use of digital artifacts. Digital artifacts as bits and bytes differ from physical artifacts as they can be characterized as editable, interactive, open/reprogrammable, and distributed (Kallinikos et al. 2013). They can thus be easily modified and scaled. Remane et al. (2017) distinguish pure digital and digital-enabled business models. Pure digital business models, like Google as a search engine or Airbnb as an online broker, create and capture the value and build their business model on digital artifacts only, without the use of physical assets in their value creation activities. Digital-enabled business models like sensor-as-a-service business models require both - physical assets and digital artifacts - for the creation of value. Pure digital and digital-enabled business models alike share the characteristics of digital artifacts. In this chapter, we will focus our thoughts on pure digital business models. In order to shed light on the differences in the development of minimum viable products, we follow the 4-C digital business model typology of Wirtz (2019). The author distinguishes four business model categories for B2C-businesses with different business model types (see the business model categories and types in Table 2). ${ }^{1}$ These business model types are deviated based on the functional aspects of the value proposition of the business model (Wirtz 2019).

\subsection{Development Processes of Digital Business Models}

The development of an attractive, repeatable, and scalable business model is the objective of every firm and has received a lot of attention in research in the last ten years. Following Osterwalder et al. (2014), the identification of a replicable and scalable business model builds upon product-market fit and a business model fit. Fit can be understood as a situation where the product or the business model favorably matches the conditions in the environment of a firm (Miles and Snow 1984). This idea is consistent with the contingency theory in strategic management, where the fit of a company's activities with its environment is an essential prerequisite for a company to exist. Achieving a situation of fit requires a dynamic search process that aligns the business with its environments and deploys resources alike (Miles and Snow 1984; Blank 2010).

Entrepreneurs make their decisions in circumstances of high uncertainty and causal ambiguity (Furr and Ahlstrom 2011). Customer needs are unknown in the early stages, and proper solutions, technologies, or business models need to be

\footnotetext{
${ }^{1}$ In addition, Wirtz (2019) discusses four B2B-business model categories for digital businesses.
} 
Table 2 Business model typologies (reference to Wirtz 2019)

\begin{tabular}{|c|c|c|}
\hline Business model category & Business model types & Examples \\
\hline \multirow{4}{*}{$\begin{array}{l}\text { Content } \\
\text { compilation of content, depiction } \\
\text { and provision of content on } \\
\text { domestic platform }\end{array}$} & e-information & $\begin{array}{l}\text { wsj.com, } \\
\text { handelsblatt.com, } \\
\text { Wikipedia }\end{array}$ \\
\hline & e-entertainment & $\begin{array}{l}\text { partypoker.com, Spotify, } \\
\text { WoW }\end{array}$ \\
\hline & e-education & udacity, udemy, coursera \\
\hline & e-infotainment & nba.com, sport1.de \\
\hline \multirow{4}{*}{$\begin{array}{l}\text { Commerce } \\
\text { Initiation and/or settlement of } \\
\text { business transactions }\end{array}$} & e-attraction & AdSense, Shopping.com \\
\hline & e-bargaining/negotiation & eBay, Groupon \\
\hline & e-transaction & Paypal, Klarna, Bitcoin \\
\hline & e-tailing & $\begin{array}{l}\text { Amazon, Expedia, book a } \\
\text { tiger, zappos.com }\end{array}$ \\
\hline \multirow{3}{*}{$\begin{array}{l}\text { Context } \\
\text { Classification and systematization } \\
\text { of information available on the } \\
\text { Internet }\end{array}$} & Search engines & $\begin{array}{l}\text { Google, Yahoo, Bing, } \\
\text { DuckDuckGo, } \\
\text { Indeed.com }\end{array}$ \\
\hline & Web directories & Yahoo.com, \\
\hline & Book-marking & Citeulike.org \\
\hline \multirow[t]{2}{*}{$\begin{array}{l}\text { Connection } \\
\text { Creation of the possibility to } \\
\text { exchange information in networks }\end{array}$} & $\begin{array}{l}\text { Intraconnection } \\
\text { (Community) }\end{array}$ & $\begin{array}{l}\text { Facebook, Snapchat, } \\
\text { Skype, Flickr, Yelp, } \\
\text { Gmail, Dropbox }\end{array}$ \\
\hline & Interconnection & $\begin{array}{l}\text { earthlink.net, sonic.net, } \\
\text { att.com, t-mobile.com }\end{array}$ \\
\hline
\end{tabular}

explored. Decision making under uncertainty and causal ambiguity is constrained by various types of cognitive biases - e.g., confirmation bias, overconfidence bias, or escalation of commitment (Zhang and Cueto 2015). This includes the development of a product without a validated customer problem or the scaling of activities without an attractive business model. Under the influence of cognitive biases in an uncertain context, entrepreneurs are ignorant to disconfirm information (confirmation bias), too optimistic about their success chances (overconfidence), and susceptible to continue investing in an unpromising business idea (escalation of commitment). These cognitive biases can lead to premature scaling of activities, which means the inappropriate scaling of activities. Premature scaling is thus one of the major drivers of startup failure (StartupGenomeReport 2011; CBInsights 2018). To improve decision making under high uncertainty, effective entrepreneurs run experiments to validate/invalidate critical business assumptions (Ries 2011; Blank and Dorf 2012; Gambardella et al. 2018). The process of experimenting to validate/invalidate critical assumptions can be understood as deliberate and dynamic search process to find an attractive, replicable, and scalable business model and is core to the lean startup approach (Blank 2010; Maurya 2012; Ries 2011; Frederiksen and Brem 2017). Ries (2011) suggests a build-measure-learn loop, where an entrepreneur identifies the most critical business assumptions, builds an experiment to test these assumptions, measures the user behavior, and creates learnings from the gathered data (Fig. 1). 


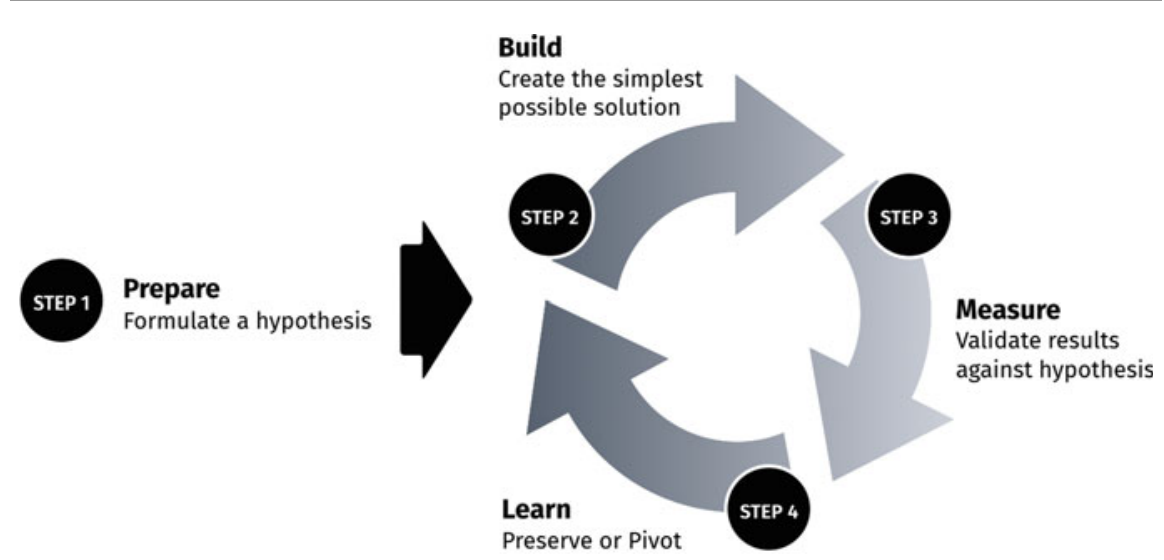

Fig. 1 Build-measure-learn loop (reference to Ries 2011)

These learnings include the information on the falsification or corroboration of the tested assumption and guide the entrepreneurs' decision making to either pivot to a new/adapted idea or to persevere on the current path (Ries 2011; Bajwa et al. 2017). The challenge with the build-measure-learn loop is that the infinite character of the loop gives entrepreneurs no guidance when to change the nature of experiments. It is not very practical nor useful to try to validate everything. But what is important is to validate the things that really matter to the business. It does not matter how many hypotheses an entrepreneur validates if none of them is critical for the success of the business. The ability to zoom out and clear the big picture is highly important to run successful iterations that matter. In practice, we see quite often entrepreneurs that use the iteration in an early stage to validate features - which is great in general - but forget to validate the value proposition first. This can be seen as premature scaling because an entrepreneur loses sight of the critical assumptions.

Another important cornerstone of the lean startup approach is the development of experiments that create targeted learning at a minimum investment of time and money. One instrument to create this fast learning is a minimum viable product (MVP), which is a specific experiment (Ries 2011). There has been a lot of confusion on the term minimum viable product. Some authors and practitioners equal the MVP with every potential form of a business experiment (e.g., a customer interview), others equal an MVP with a prototype, etc. (Duc and Abrahamson 2016). This missing clarity does not reduce complexity but adds complexity for entrepreneurs and does thus not help to structure the development process of a venture.

In the subsequent chapter, we aim to offer a structural approach to validate/invalidate the essential components of digital business models. In addition, we aim to identify the specifics that different business model types encounter when they are tested. 


\section{Conceptual Model/Empirical Insights}

\subsection{Venture Pyramid to Iteratively Develop Digital Business Models}

Following the ideas of Ellis (2013), Osterwalder et al. (2014) and Göcke (2017b), we introduce the venture pyramid as a concept to structure the deliberate and dynamic search process to identify business model fit. The venture pyramid structures the most critical business assumptions. The most critical assumptions reside at the bottom of the pyramid as the foundation of the business and have the highest magnitude of impact in case they prove wrong. This includes required changes over a certain period of time. It is important to highlight that there is no "one-size-fits-all" approach to the venture pyramid and that, depending on the scenario, different foundations are possible to start from (e.g., founders' competence, a technology, or a market need). For the following, we are taking market attractiveness as the foundation of the venture pyramid to make the process tangible. However, starting with a different foundation (e.g., the problem-solution fit before dealing with the market) might sometimes be a better way to get started. As with everything, every step in an entrepreneurial venture needs careful decision making without falling into analysis-paralysis (Fig. 2).

At the bottom of the pyramid as the foundation of the business lays an attractive group of potential customers (market attractiveness: seize/growth of group). Building on top of an attractive group of potential customers, we see the existence of a pressing customer pain of this group of potential customers as the next fundamental layer of critical assumptions (customer-problem fit). At the level of problem-solution fit, we aim not only to clarify if the customer favors our solution but also if customers are willing to pay for the solution. We suggest to test the critical assumptions at problem-solution fit only by the communication of value proposition and price but without enabling customers to experience the value proposition (e.g., with a landing page smoke test). Without the customers' willingness to pay, the development of a product or the supply-side of a business would

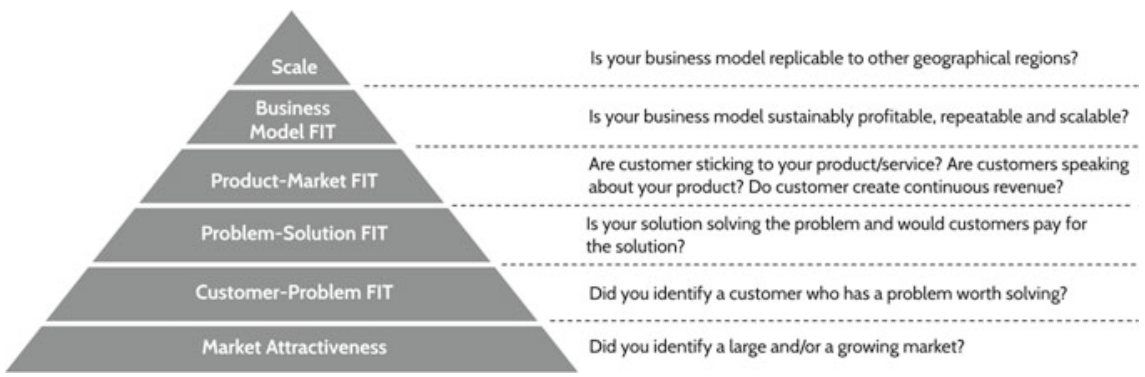

Fig. 2 Venture pyramid to structure the search process of a business model (reference to Göcke 2017a) 
not be required at all. A CBInsights (2018) analysis of startup failures shows that a majority of startups fail because of a missing market need. Assuring that this market need exists is central to the first levels of the venture pyramid (e.g., customer segments, problems value proposition). Whenever we work with the build-measure-learn iteration, it is very important to understand the big picture and to be as precise as possible with the hypothesis because sometimes small changes in the details lead to a very different result. For example, if you want to validate a feature or attribute of your product or service, just changing the customer segment gives a completely different result. Think about developing a bike. If you change the customer segment from a 23-year-old male athlete to a 34-year-old mother of two children, the bike looks completely different. Sure, one could argue that this is common sense but as entrepreneurs, we do not want to work based on common sense but on validated knowledge. And exactly, this is the reason why the buildmeasure-learn iteration is so useful and appreciated by many entrepreneurs. After having identified the demand at a particular price point, startups can test the experience of their value proposition by offering a minimum viable product. At this level, the product is handed to customers, and startups can validate/invalidate whether the product gets traction through continuous revenue, retention, and referral (McClure 2007; Croll and Yoskovitz 2013), which we see as product-market fit (Dennehy et al. 2016). With achieving a business model fit, startups (in)validate the operations of a business model. Here, it is central to identify incremental profits for every new user (action). At the scaling level, startups need to validate/invalidate what elements of their business model require adaptation to local contexts and what elements can be standardized (Göcke 2016).

There are multiple options for an entrepreneur at every level of the venture pyramid to choose and to validate/invalidate. Many potential customer groups with a great variety of problems exist in the field. And there are multiple ways to solve a customer's problem. A startup's aim is to identify the solution that is not only a local maximum but a global maximum (Sommer et al. 2009), so the best possible solution for the customer group that generates the highest willingness to pay. The same is true for the product. A startup will choose to develop a minimum viable product out of a number of alternatives, again aiming to globally maximize the return identified alternative. We suggest illustrating the different levels of the venture pyramid with various circles that illustrate the possible alternatives at every level (Frederiksen and Brem 2017). The decisions are path-dependent and limited by a startup's capabilities (Frederiksen and Brem 2017) (Fig. 3).

With every new build-measure-learn loop at the different levels of the venture pyramid, a startup runs through the process of identifying and validating the most attractive alternative at a particular level. A frequently used approach to structure this creative process is the framework "Double Diamond" (Design Council 2019). The double diamond is originally split into a problem space/idea space (left diamond) and the solution space (right diamond). Both diamonds follow the same structure: one divergent thinking phase (the left side of each diamond) and one convergent thinking phase (the right side of the diamond). Divergent thinking requires a startup team to think about getting as many alternatives on paper as 


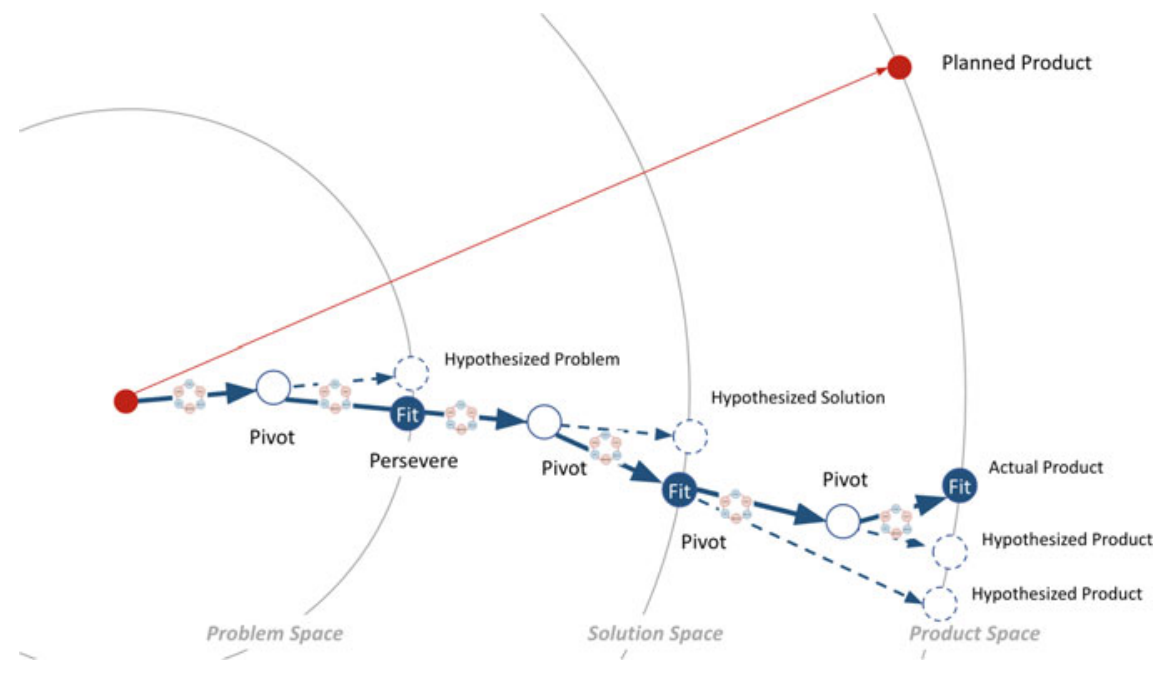

Fig. 3 Path of deliberate entrepreneurial experimentation with the venture pyramid (reference to Göcke 2017b)

possible to increase the probability of identifying the global maximum. At every level of the venture pyramid, there are different creativity techniques (e.g., analogies or patterns) that can be applied to support the process of divergent thinking. Convergent thinking takes an analytical approach to identify the best possible alternative. In our understanding here, the first diamond aims to identify the riskiest assumptions at the particular level of the venture pyramid. In short, through divergent thinking, a startup ideates a range of alternative assumptions, and the convergent thinking processes allow the startup to select the riskiest assumption. The end of the phase often marks the so-called How might we (HMW) question (Knapp et al. 2016), which opens the second diamond and asks how this assumption can be tested. The second diamond reflects the ideation (divergent thinking), selection (convergent thinking), and finally the conduction of an appropriate experiment at every level of the venture pyramid. To support the ideation of alternative experiments at the level of product-market fit, we match different digital business models with patterns of minimum viable products in the subsequent chapter.

\subsection{Identifying Minimum Viable Products for Digital Business Models}

There are multiple ways to test the most critical assumptions at every level of the venture pyramid. At the lowest level of the venture pyramid, startups can choose to use secondary market research or behavioral data (e.g., Google keyword searches) 
to identify if a certain topic catches attention. The level of customer-problem fit is best achieved with the help of intense customer discovery interviews. At the level of problem-solution fit, the core idea is to run a pre-sales test, where potential customers signal their willingness to buy the product at a particular price. We define experiments at this level of the venture pyramid as smoke tests. These smoke tests can be triggered by landing pages, an email, or a customer interview.

Following Ries $(2011,2016)$ and Duc and Abrahamson (2016), we distinguish four types of minimum viable products (MVP) that are able to create the targeted product experience at a low level of cost in order to validate product-market fit:

- The single feature MVP focuses on the development and implementation of the most important feature of a particular product. A very prominent example is Google's search engine. Google started with a performing search engine to find manually listed Web sites.

- Developing a concierge MVP means being in contact with the end-user. The founding team is personally involved in delivering value to the customer. Airbnb is an often-cited example of this experiment. The owners identified that design conference visitors in San Francisco were not able to book a hotel. As a consequence, the founders offered three airbeds and breakfast in their flat.

- The Wizard-of-Oz MVP tricks the user as the user experiences the product or service with full functions and as completely automated, but the startup mocks the process in the back. Zappos is one startup that had to validate that people were willing to buy shoes online. The front end illustrated a fully automated process, but in the back, everything was operated by humans.

- Groupon is one startup that used a piecemeal MVP to validate the continuous demand of users. A piecemeal MVP means that the initial version of a product is developed on standardized components.

Table 3 aims to provide examples of MVPs for the different digital business models to work as inspiration for startups to find a way to achieve a product-market fit and for researchers to initiate more intense research on MVP types. The use of the 4-C business model typology focuses on the functional aspects of digital business models. Different approaches to business model typologies (e.g., with a stronger focus on operations) might add additional value to the development of minimum viable products.

\subsection{Case Studies}

In order to illustrate our thoughts with some practical insights, we have created two different case studies with startups based in Germany (Siggelkow 2007). We conducted structured interviews that followed an interview guideline. The respective companies have been selected randomly. 

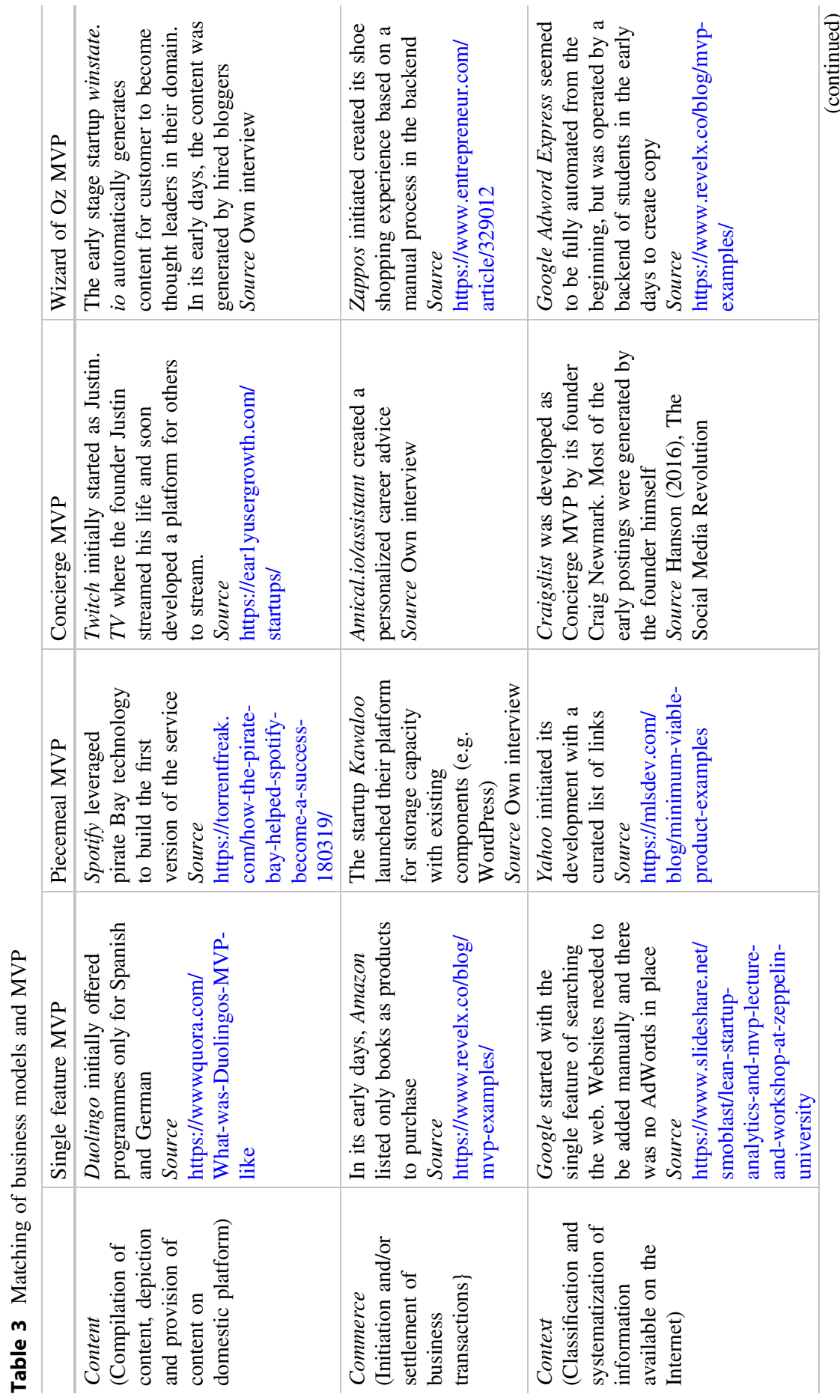


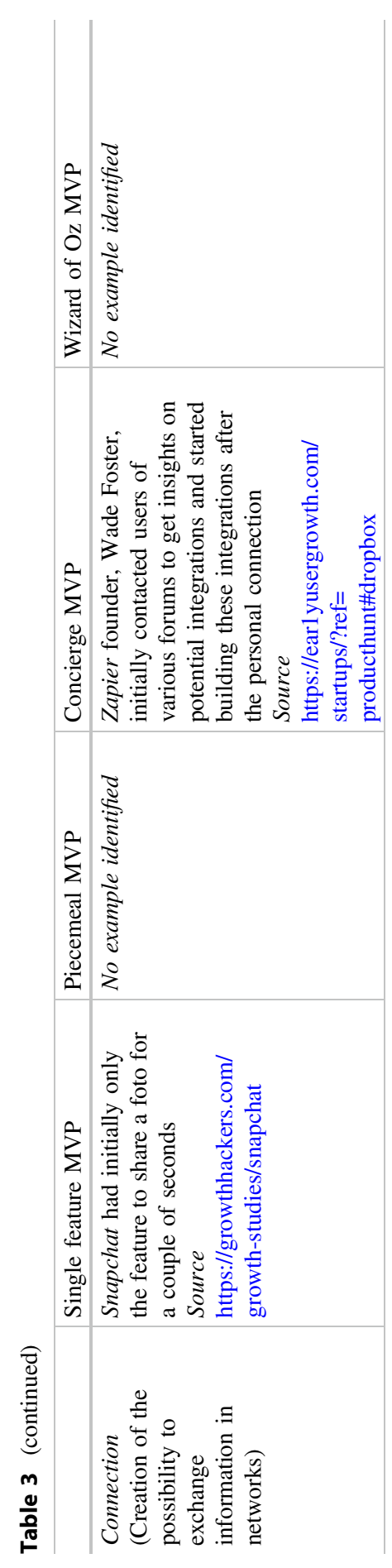




\subsubsection{Electry: The Linkedin for Skilled Blue-Collar Workers}

Julian Lindinger and Konrad Geiger started their ventures' journey as students of the WHU in 2018 with the objective to solve a big problem of HR departments - the attraction of talent for their company. In addition, the founders observed that they frequently recommended others for jobs, but that there were no financial benefits for them to do so. They were thus doing the job of headhunters without benefiting from the value they created. The idea of amical.io as UBER for head-hunting was born. The idea can be understood as an e-attraction business model, where job offers are aggregated and users are incentivized to recommend others for the jobs. With a high level of excitement and great support from family and friends, Julian and Konrad decided to build the platform and launched the service at the end of 2018. They intuitively chose to build a Wizard-of-Oz MVP, where they mocked the B2B-processes. After launching the service, they soon realized that the platform missed the required traction from the user side. This was in conflict with one of the riskiest assumptions they had at the time-great jobs will attract talent to our platform. The business did not show traction although it had very attractive vacancies, e.g., from Quora and Zeitgold, on their platform. Many companies were attracted by the solution, but it turned out that the potential employees and recommenders did not choose the platform. After several interviews with users, the amical.io founders identified that the most important component is to attract talent because jobs will come anyway. Thus, they decided to pivot to future employees and developed a concierge MVP for a digital career assistant — amical.io/assistant. Every time a talent signs up for career assistance and expresses the interest to take on a new opportunity, the amical team starts to search for potential jobs. They are thus reversing the recruitment process from a head-hunting to a job-hunting model. Simultaneous to testing the amical.io/assistant in general, the team tested attractive verticals in the recruitment markets, where specific job profiles are highly demanded. After experiencing the costly pivot from the recommendation platform, amical.io tested its critical business assumptions in a more lean and rigorous manner. Based on the rigid experimentation, the team developed "Electry - the Linkedin for skilled blue-collar workers". In 2020, Electry has been accepted for the YCombinator acclerator programme and is now receiveing seed funding.

\subsubsection{Acomodeo: Serviced Appartments for Corporate Travelers}

Acomodeo was founded by David Wohde and Eric-Jan Krausch and was named as one of Europe's Top 100 Proptech Startups in 2018. Today, Acomodeo is leading the market of long-stay apartment stays for business travelers and working with a good majority of German and international corporates. But that is not what Acomodeo started as. Acomodeo was born out of the market need for long-stay apartments for journalists during major sports events like the Olympics or the Soccer World Cup. Working in the travel industry, David first served this market need by searching, acquiring, and connecting apartments with journalists looking for a long-stay apartment. This was their first concierge MVP that existed before the company was actually founded. Following the described process of business model discovery, the first three pillars of the venture pyramid were already covered and 
validated in a very early stage. Building on these early successes and confident from the early market feedback, David and Eric started the business to work on a digital marketplace for long-stay apartment bookings. After finalizing the first version of the platform, Acomodeo had to learn that the market is much harder to acquire compared to the times of sporting events. Their first version of the platform was serving at individual business travelers to book long-stay apartments directly with them. However, business travelers in this category are bound to corporate business travel policies most of the time and could not just book their apartment with Acomodeo. In fact, their users of the product were business travelers. However, the buyer was the corporate travel manager that they had to serve first. This is a great lesson on product-market fit and the importance of understanding customer segments from a user and buyer perspective. Product-market fit is also a lot about understanding the buyer and the user (which is not always the same). Fast forward, David and Eric pivoted the platform to serve the needs of the corporate business travel manager and included the features they needed to approve Acomodeo as a platform for corporate travelers.

\section{Practical Implications for Digital Entrepreneurs}

In the previous thoughts, we have seen that many digital startups leverage the lean startup approach but have challenges in applying it to their own journey. Our presented thoughts on the venture pyramid and MVPs for digital business models are aiming at structuring the search process for an attractive business model. This approach is designed to reduce uncertainty (not to eliminate it) and to provide guidance on the challenging journey. The different types of MVPs shall inspire startups to identify a way of testing and validating their business idea in the search process to an attractive business model. We understand the startup process as two-fold. While a startup searches for a repeatable and scalable business model, it also needs to achieve operational excellence in team structuring, management, accounting, sales, and so on. Additionally, reality will always bring surprises along the way. We have seen great business models that work out extremely well, but then within weeks, one of the key partners goes bankrupt and nothing seems to work anymore. We have not covered this in this chapter, but it should be within the radius of awareness of every entrepreneur, and it stresses the urge to regularly work and update the business model.

We furthermore believe that every entrepreneurial discovery process is only as good as the willingness of the entrepreneurs to learn, adapt, and challenge their own thoughts and ideas. Or simply put, the success of a venture lies in the execution of the idea rather than in the methodology itself. Every entrepreneur needs to decide individually how they want to build their business and what tools to use at the right time. As a general take away, we recommend embracing iterative validation based on hypotheses, a mindset to test, and a divergent and convergent thinking processes. 


\section{References}

Bajwa, S. S., Wang, X., Duc, A. N., \& Abrahamsson, P. (2017). Failures to be celebrated. An analysis of major pivots of software startups. Empirical Software Engineering, 22, 2373-2408.

Blank, S. (2010). What's a startup? First principles. https://steveblank.com/2010/01/25/whats-astartup-first-principles/. Retrieved October 09, 2019.

Blank, S., \& Dorf, B. (2012). The startup owners manual: The step-by-step guide for building a great company. K\&S Ranch.

Cavalcante, S. A., Kesting, P., \& Ulhoi, J. P. (2011). Business model dynamics and innovation. (Re)establishing the missing linkages. Management Decision, 8(3), S. 1327-1342.

CBInsights. (2018). The top 20 reasons startups fail. Online: https://www.cbinsights.com/ research/startup-failure-reasons-top/. Retrieved October 09, 2019.

Chesbrough, H., \& Rosenbloom, R. (2002). The role of business model in capturing value from innovation. Evidence from XEROXCorporation's technology spin-off companies. Industrial and Corporate Change, 11 (3), S. 529-555.

Clauss, T. (2017). Measuring business model innovation. Conceptualization, scale development and proof of performance. $R \& D$ Management, 47(3), 385-403.

Croll, A., \& Yoskovitz, B. (2013). Lean analytics. Use data to build a better startup faster. O'Reilly and Associates.

Dennehy, D., Kasraian, L., O'Raghallaigh, P., \& Conboy, K. (2016). Product market fit frameworks for lean product development. In $R \& D$ Management Conference, June 2016, Cambridge (UK).

Design Council (2019). The double diamond. https://www.designcouncil.org.uk/news-opinion/ double-diamond-15-years. Retrieved July 16, 2020.

Duc, A. N., \& Abrahamson, P. (2016). Minimum viable product or multiple facet product? The role of MVP in software startups. In International Conference on Agile Software Development (XP 2016). Agile Processes in Software Engineering, and Extreme Programming (pp 118$130)$.

Ellis, S. (2013). The startup pyramid. Online: https://www.startup-marketing.com/the-startuppyramid/. Retrieved October 09, 2019.

Frederiksen, D. L., \& Brem, A. (2017). How do entrepreneurs think they create value? A scientific reflection of Eric Ries' Lean Startup Approach. International Entrepreneurship Management Journal, 13, 169-189.

Furr, N. R., \& Ahlstrom, P. (2011). Nail it then scale it. The entrepreneur's guide to creating and managing breakthrough innovation. NISI Institute.

Gambardella, A., Camuffo, A., Cordova, A., \& Spina, C. (2018). A scientific approach to entrepreneurial decision making: Evidence form a randomized control trial (October 16, 2018). Forthcoming in Management Science.

Gassmann, O., Frankenberger, K., Csik, M. (2014). The business model navigator. 55 models that will revolutionise your business. Financial Times Prent.

Ghaziani, A., \& Ventresca, M. J. (2005). Keywords and cultural change: Frame analysis of business model public talk, 1975-2000. Sociological Forum, 20(4), 523-559.

Ghezzi, A. (2019). Digital startups and the adoption and implementation of lean startup approaches: Effectuation, bricolage and opportunity creation in practice. Technological Forecasting and Social Change, 146, 945-960.

Göcke, L. (2016). Geschäftsmodellentwicklung im Spannungsfeld multinationaler Unternehmen. Eine Fallstudie am Beispiel der Elektromobilität. Wiesbaden: Springer.

Göcke, L. (2017a). Why the Venture Pyramid changes how you think about innovation. https:// www.swan.ventures/blog/2017/8/22/venture-pyramid. Retrieved July 15, 2020.

Göcke, L. (2017b). How to track progress in the Build-Measure-Learn Loop. https://www.swan. ventures/blog/2017/8/31/howto-track-progress-in-the-build-measure-learn-loop. Retrieved July $15,2020$. 
Kallinikos, J., Aaltonen, A., \& Marton, A. (2013). The ambivalent ontology of digital artifacts. MIS Quarterly, 37, 357-370.

Knapp, J., Zeratsky, J., Kowitz, B. (2016). Sprint. How to solve big problems and test new ideas in just five days. Simon \& Schuster.

Maurya, A. (2012). Running lean. Iterate from Plan A to a Plan that Works. O'Reilly and Associates.

McClure, D. (2007). Product marketing for pirates: AARRR! Online: https://500hats.typepad.com/ 500blogs/2007/06/internet-market.html. Retrieved October 08, 2019.

Miles, R. E., \& Snow, C. C. (1984). Fit, failure and the hall of fame. California Management Review, 26(3), 10-28.

Osterwalder, A., Pigneur, Y. (2011). Business model generation. Ein Handbuch für Visionäre, Spielveränderer und Herausforderer. Frankfurt am Main: Campus.

Osterwalder, A., Pigneur, Y., Bernarda, G., \& Smith, A. (2014). Value proposition design. How to create products and services customers want. New York: Wiley.

Remane, G., Hanelt, A., Tesch, J. F., \& Kolbe, L. M. (2017). The business model pattern database. A tool for systematic business model innovation. International Journal of Innovation Management, 21(1), 1750004 (61 pages).

Ries, E. (2011). The lean startup. How constant innovation creates radically successful businesses. Penguin Random House.

Ries, E. (2016). The leader's guide to adopting lean startup at scale. Kickstarter.

Schneider, S., \& Spieth, P. (2013). Business model innovation. Towards an integrated future research agenda. International Journal of Innovation Management, 17(1), S. 1340001-11340001-34.

Siggelkow, N. (2007). Persuasion with case studies. Academy of Management Journal, 50(1), $20-24$.

Sommer, S. C., Loch, C. H., Dong, J. (2009). Managing complexity and unforeseeable uncertainty in startup companies. An Empirical Study. Organization Science, 20 (1), 118-133.

StartupGenome. (2011). Startup genome report. A new framework for understanding why startups succeed. https://s3.amazonaws.com/startupcompass-public/StartupGenomeReport1_Why_ Startups_Succeed_v2.pdf. Retrieved October 06, 2019.

Teece, D. (2010). Business models, business strategy and innovation. Long Range Planning, 43, 172-194.

Wirtz, B. W. (2019). Digital business models. Concepts, models, and the alphabet case study. Springer Nature Switzerland.

Zhang, S. X., \& Cueto, J. (2015). The study of bias in entrepreneurship. Entrepreneurship theory and practice.

Zott, C., Amit, R., \& Massa, L. (2011). The business model: Recent developments and future research. Journal of Management, 37(4), 1019-1042.

Open Access This chapter is licensed under the terms of the Creative Commons Attribution 4.0 International License (http://creativecommons.org/licenses/by/4.0/), which permits use, sharing, adaptation, distribution and reproduction in any medium or format, as long as you give appropriate credit to the original author(s) and the source, provide a link to the Creative Commons license and indicate if changes were made.

The images or other third party material in this chapter are included in the chapter's Creative Commons license, unless indicated otherwise in a credit line to the material. If material is not included in the chapter's Creative Commons license and your intended use is not permitted by statutory regulation or exceeds the permitted use, you will need to obtain permission directly from the copyright holder.

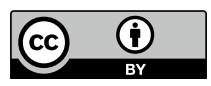

